
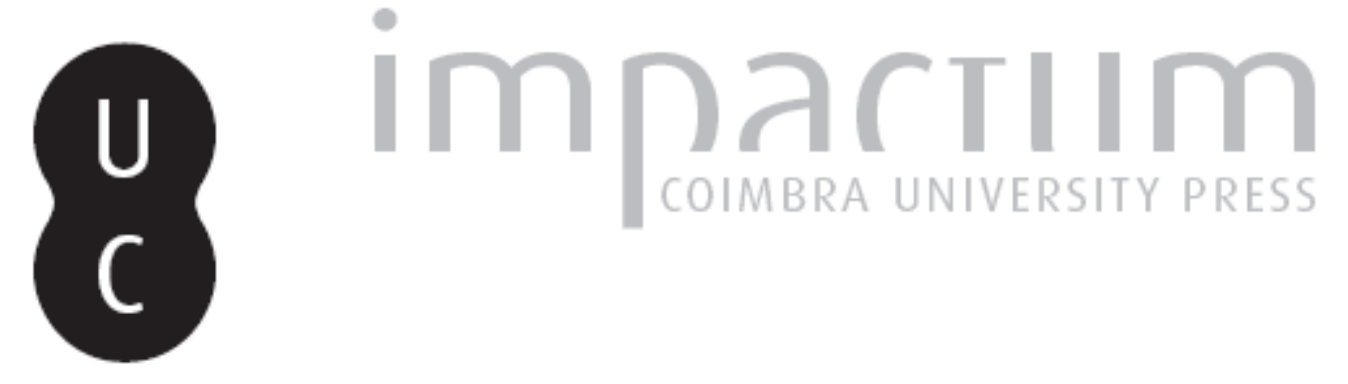

\title{
Turismo para a construção de uma paisagem cultural: sedução, símbolo, autenticidade
}

\author{
Autor(es): $\quad$ Cabrita, Filipa
}

Publicado por: Editorial do Departamento de Arquitectura

URL

persistente:

URI:http://hdl.handle.net/10316.2/37221

DOI:

DOI:http://dx.doi.org/10.14195/1647-8681_1_19

Accessed : $\quad$ 26-Apr-2023 13:05:55

A navegação consulta e descarregamento dos títulos inseridos nas Bibliotecas Digitais UC Digitalis, UC Pombalina e UC Impactum, pressupõem a aceitação plena e sem reservas dos Termos e Condições de Uso destas Bibliotecas Digitais, disponíveis em https://digitalis.uc.pt/pt-pt/termos.

Conforme exposto nos referidos Termos e Condições de Uso, o descarregamento de títulos de acesso restrito requer uma licença válida de autorização devendo o utilizador aceder ao(s) documento(s) a partir de um endereço de IP da instituição detentora da supramencionada licença.

Ao utilizador é apenas permitido o descarregamento para uso pessoal, pelo que o emprego do(s) título(s) descarregado(s) para outro fim, designadamente comercial, carece de autorização do respetivo autor ou editor da obra.

Na medida em que todas as obras da UC Digitalis se encontram protegidas pelo Código do Direito de Autor e Direitos Conexos e demais legislação aplicável, toda a cópia, parcial ou total, deste documento, nos casos em que é legalmente admitida, deverá conter ou fazer-se acompanhar por este aviso.

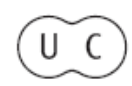




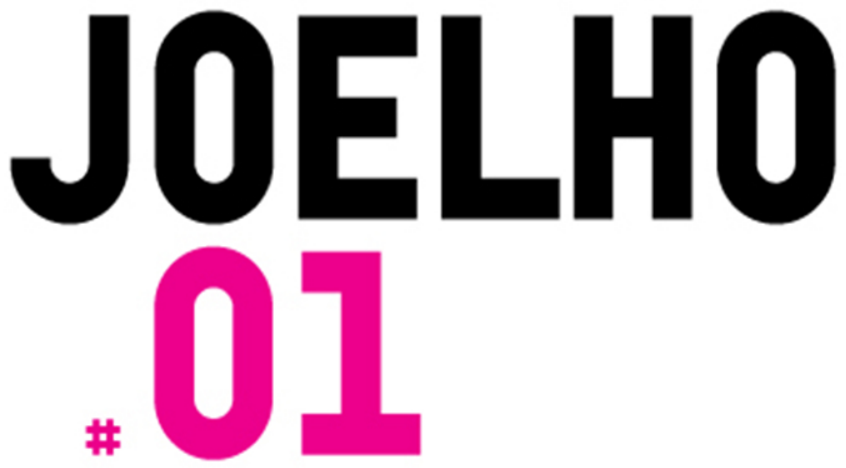

\section{MULHERES NA ARQUITECTURA}

Jorge Figueira

Coordenação

Silvana Rubino

Carla Lopes

Liliana Carvalho

Joana Bem-Haja

Filipa Cabrita

Inês Antunes

Telma Silva

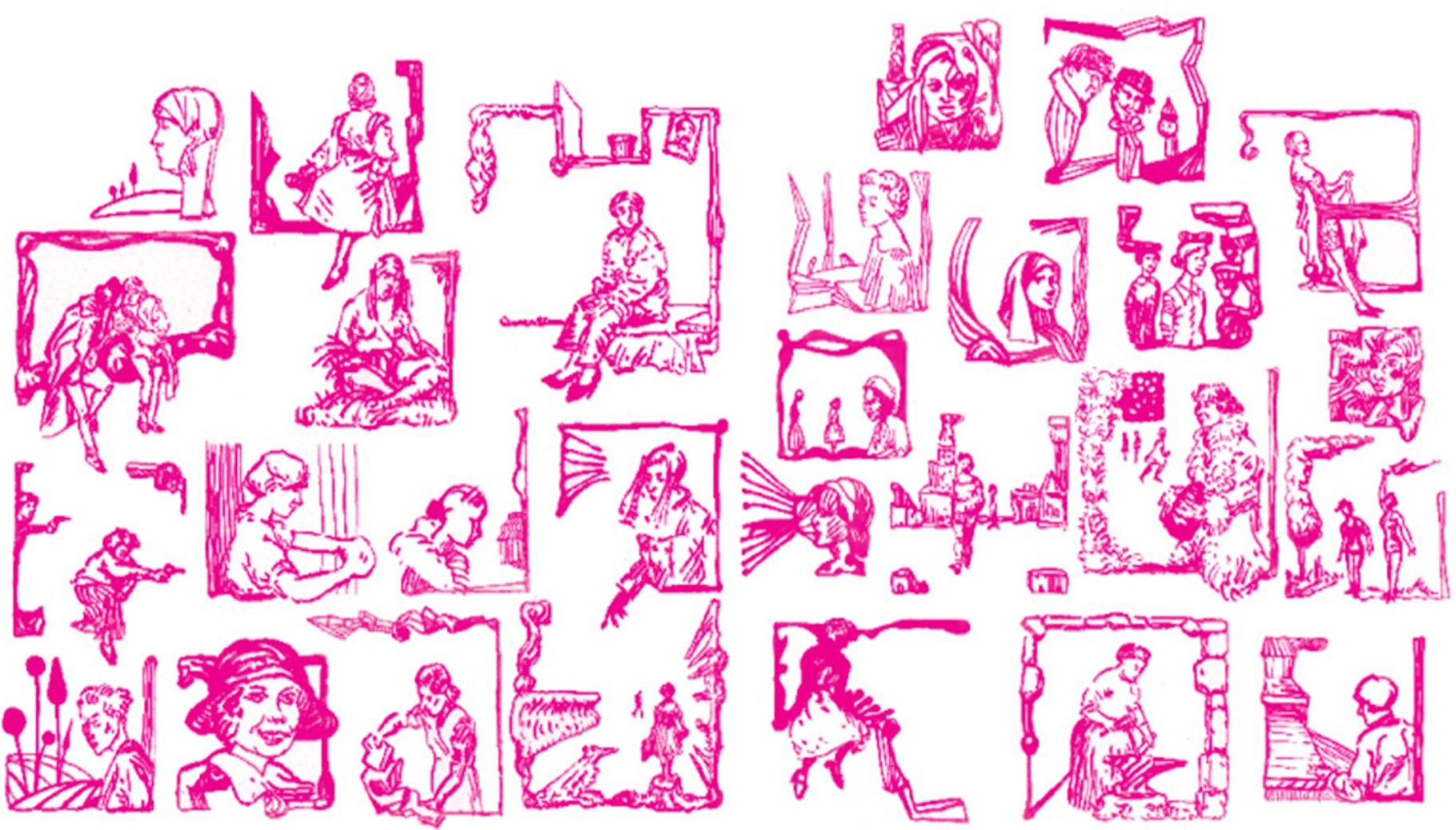


Turismo para a

construção de uma

paisagem cultural.

Sedução, símbolo,

autenticidade

Filipa Cabrita

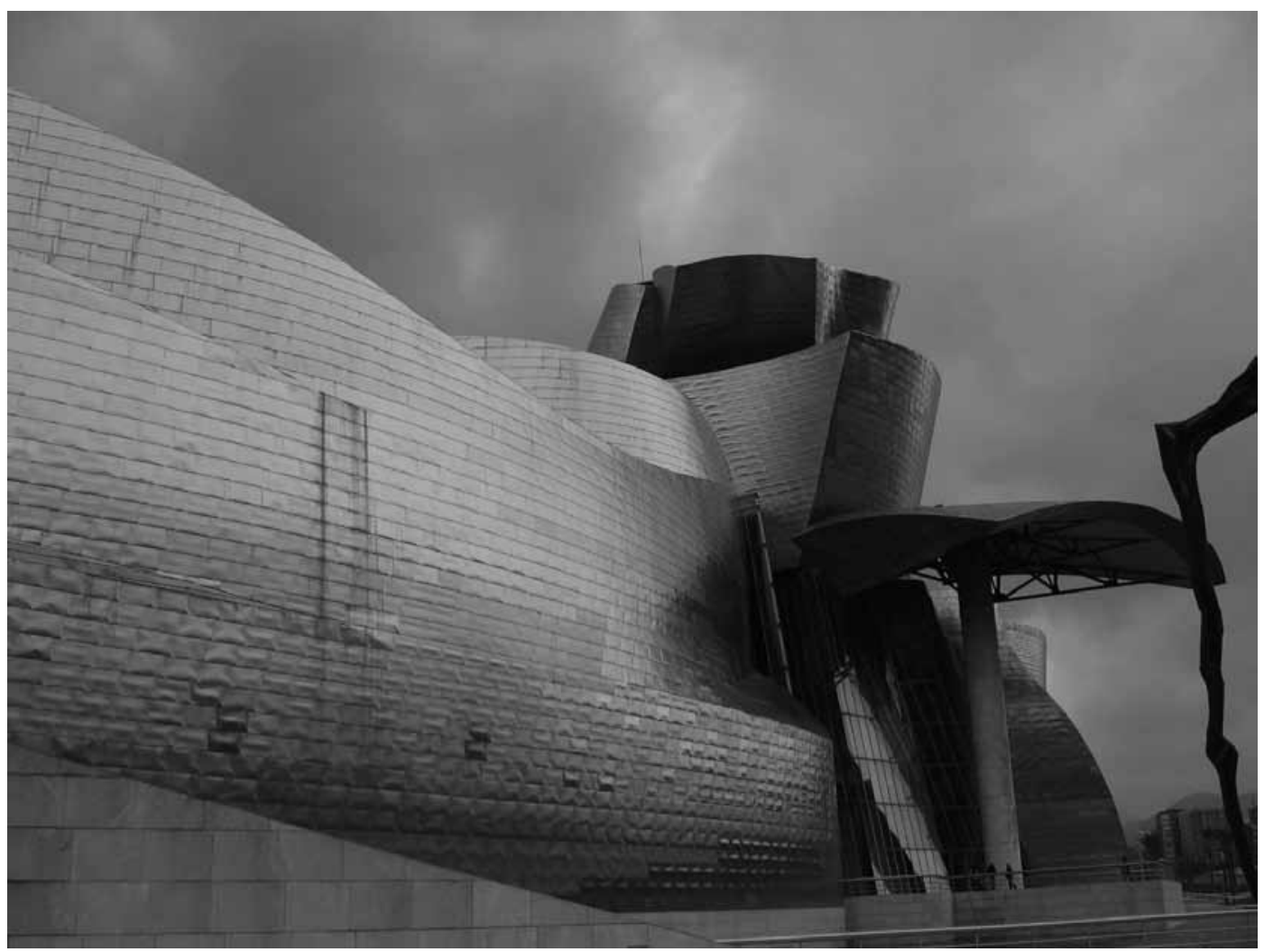

Fotografia Turística do Guggenheim, Bilbao 
Esta é uma visita diacrónica a alguns dos mais determinantes temas que partilham e cruzam com uma história conceptual do Turismo e da teoria da arquitectura. É acima de tudo um trabalho de reflexão motivado por uma vontade de compreensão de um processo que é hoje inerente à própria ideia de cultura e que é responsável por um novo paradigma definido pelo binómio global/local que marca a contemporaneidade. Esta visita parte dos pressupostos de que o Turismo é actualmente um fenómeno de presença incontornável que promove múltiplas consequências nos hábitos e inter-relações sociais e consequentemente na apropriação do território. Também parte do pressuposto que é um fenómeno complexo e transversal que se relaciona com a totalidade das esferas da actividade humana sejam elas dinâmicas culturais, económico-financeiras ou politico-ideológicas. O seu objectivo passa, por isso, por fazer uma leitura panorâmica deste fenómeno enquanto motivador dos processos de construção ou consolidação de uma ideia de paisagem cultural, para perceber como é que este paradigma se pode constituir hoje num tema na produção arquitectónica.

O problema central da história conceptual do Turismo remete para a questão de saber que condições precisaram de estar reunidas, no imaginário do sujeito, para dar o significado à viagem que hoje lhe é atribuído. Porque, à análise dos fenómenos, e na demarcação dos espaços uns dos outros, confronta-se a dificuldade de definição dos limites a partir dos quais se pode afirmar onde começa e acaba um espaço turístico, ou não fossem os seus limites o resultado de uma época e do nível operatório de uma cultura. É por isso evidente a impossibilidade de se compreender a emergência do turismo sem a articular com um conjunto de condições gerais características da Europa ocidental, que terão emergido com a modernidade, nomeadamente pela introdução de uma ideia de tempo-livre proporcionada pela Revolução Industrial como explica Dean MacCannell: "Industrial society bound men to its jobs, but because extreme specialization and fragmentation of tasks in the industrial process, the job did not function to integrate its holder into a synthetic social perspective, a world view. As solution to the problem culture, industrial work is a failure. It repulses the individual, sending him away to search for his identity or soul in off-the job activities" (MacCannel, 1976:36).

Le Corbusier na sua proposta para um modelo urbanístico moderno inclui esta novidade programática naquela que foi uma das primeiras manifestações de um arquétipo a que hoje chamamos life-style: "a generic term for specific combinations of work and leisure, is replacing "occupation" as the basis of social relationship formation, social status and social action" (MacCannel, 1976:6). E na melhor tradição positivista esta combinação tinha de ser especialmente operativa. Le Corbusier tornava clara a função das horas vagas quando afirmava que o preenchimento das horas livres é "um problema de arquitectura: a habitação; de urbanismo: a organização dos bairros residenciais, a máquina de espairecer" (Le Corbusier, 2000:187). Porque para ele "a hora do repouso é a hora de espairecer" e espairecer para Le Corbusier era acima de tudo cuidar do corpo "oito horas de repouso continuado. $\mathrm{O}$ 
urbanista deve responder. A prática do desporto deve ser acessível a todos os habitantes da cidade. $O$ desporto deve ser praticado ao lado de casa (...) para realizar essa coisa utópica, basta construir em altura" (Le Corbusier, 2000:189). E na sua proposta para uma cidade moderna, mais tarde condensada na Carta de Atenas, a construção em altura abria grandes espaços verdes ou providos de equipamentos de função regenerativa do corpo e do indivíduo para a posterior restituição "ao grande corpo social em que reinava a unidade e a ordem, um corpo limpo e saudável” (Le Corbusier, 2000: 79).

No entanto, se quisermos falar da evolução do fenómeno do Turismo, o princípio funcionalista de cidade não abrange na sua génese o programa turístico como o entendemos hoje. Principalmente porque a dinâmica do pensamento positivista, fortemente inspirada por uma ideia de ordem e progresso sugerida pela máquina, entende o indivíduo como uma abstracção, como uma peça na engrenagem, como um dado objectável que se dilui em comportamentos previsíveis. Como John Urry explica: "one of the very strong objections to modernism was that it generated uniformity, or placelessness, and was therefore unlikely to generate large numbers of buildings attractive to potential tourists who want to gaze upon the distinct" (Urry, I990: I25-I26). Porque se entendermos o fenómeno do Turismo como uma relação empírica de dimensão cultural e social, percebemos que este só se perpétua no contacto facultado pela viagem. Ou seja, se o programa do turismo é um programa empírico do extraordinário, o exercício da produção arquitectónica de modo para participar nessa dialéctica, tem de transmitir um sentido de lugar, contrário ao princípio doutrinário e reprodutível de cidade proposto pelo movimento moderno; porque é precisamente a demanda pelo único e singular que dá o mote ao Turismo. A partir do momento que é proposto um modelo genérico de cidade, a experiência turística não encontra o seu princípio da mobilidade.

Esta dimensão cultural fortemente patente na experiência turística não é no entanto exclusiva deste fenómeno. Em todas as épocas este argumento cultural foi sendo desenvolvido umas vezes de formas mais objectivas apoiadas em questões de soberania e integridade territorial outras mais inatas num demorado diálogo entre as especificidades temporais e territoriais. Mas o que o fenómeno do Turismo acrescenta é uma nova consciência da necessidade de uma diferenciação cultural especialmente no que toca à construção de argumentos de índole nacional. Esta consciência tornou-se especialmente notória naquele que foi um dos mais amotinados momentos ideológicos do Século $\mathrm{xx}$ - o período que precede à $2^{\mathrm{a}}$ Guerra Mundial. Por esta altura emergiram por toda a Europa modelos políticos de feições absolutistas que cedo instrumentalizaram o Turismo como um meio para a construção de um argumento de feições estético-politicas. Estas narrativas operavam consequentemente como um poderoso meio de mobilização ideológica que aliado a uma ideia de instrumentalização do lazer garantia a lealdade das massas. Visto como uma espécie de vidro espelhado, o Turismo era o veículo capaz de esclarecer a imagem nacional e potenciá-la para fins de estado. Porque se, por um lado, levava a imagem do país para o exterior, por outro, essa mesma imagem podia ser 
absorvida como um projecto de definição nacional. Com efeito a "instrumentalização do lazer" durante este período parece ter sido um dos meios adoptados para criar a homogeneidade necessária ao funcionamento do Estado e da mística da nação. Como explica José Santos, "a experiência turística associa-se a elementos ideológicos, de função regenerativa, de compensação do mundo laboral, de instrução, de satisfação de aspirações vivenciais, pautadas por objectivos políticos. Empregado como arma, o conhecimento adquirido da realidade exterior através do turismo vem acentuar a evidência da edificação de construções simbólicas com propósitos expressos de heterodirecção dos indivíduos e dos banhos de multidão que proporciona" (Santos, 200I: 234).

O cume do Estado totalitário é alcançado por um caminho de sedução do povo por sentimentos e não pela razão. Por isso na lógica decorrente dos poderes totalitários e nas condições sociais requeridas pelo Estado a propaganda age como um mecanismo de tutela e regulação de afectos da vida dos indivíduos. A imagem da Nação será, nestes regimes, formalizada pela mensagem de persuasão da propaganda e da publicidade turística, assim como através dos meios de comunicação social afectos ao regime. A produção da Nação e da sua identidade "passa pela objectivação de um passado no presente, sujeito a invenções e adequações, mas destinado a aureolá-las com o prestígio que a antiguidade confere" (Sobral, ı999: 84). A produção de identidade é a produção de memórias, que não se limitam à forma oral ou escrita, mas que passam pela inserção num espaço: a residência e propriedade, por um lado, o território nacional, por outro. Um espaço que é, por isso, uma base de memória, um símbolo identitário, além de uma fonte de recursos. Compreende-se assim a importância dada pelos estados - que se querem identificar como nações - ao seu património nacional (monumentos, artefactos, produtos da acção passada dos seus cidadãos) e ao território.

Em Portugal, o Estado Novo, à semelhança do que sucedeu noutros regimes seus contemporâneos, também usou um aparelho de propaganda para o legitimar - a Secretariado de Propaganda Nacional (s P N), que mais tarde se transformou no Secretariado Nacional de Informação, Turismo e Cultura Popular, geralmente conhecido pelo seu nome simplificado de Secretariado Nacional de Informação (s N I). Esta organização foi responsável, sob a direcção de António Ferro, por algumas das mais importantes e significativas iniciativas turístico-culturais do projecto de consolidação cultural do regime denominado por "Política de Espírito". Como explica Ema Pires, na sua publicação sobre turismo e propaganda no Estado Novo, "Esta "Política do Espírito" visava transmitir à "Nação" mensagens de carácter nacionalista e paternalista materializadas numa multiplicidade de práticas culturais. Para "esclarecer a nação" nos valores do nacionalismo e apelar à tradição como álibi da continuidade, a propaganda fez muitas vezes uso da ciência e das artes, cujo discurso modelou à voz do seu próprio discurso " (Pires 2003: 27). 


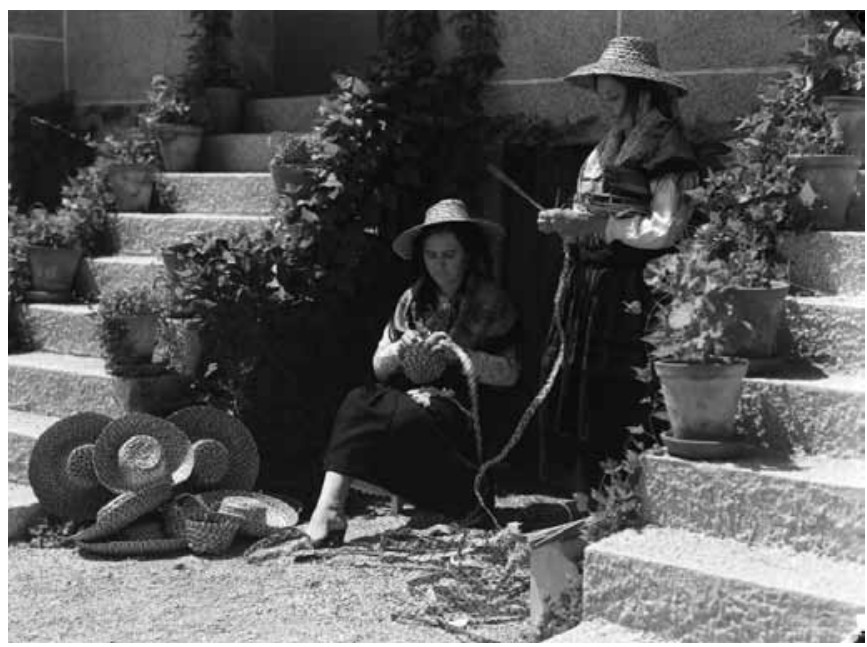

Cena de uma reconstituição viva dos ofícios rurais para o núcleo das Aldeias Portuguesas da Exposição do Mundo Português, Lisboa (1940)
"Foi como o maior optimismo (...) que o Secretariado de Propaganda Nacional recebeu, (...) no quadro das suas actividades, o encargo do problema do turismo. Há muito que sonhávamos, quase infantilmente, com essa caixa de lápis de cores, com esse pretexto para elevar o nível do nosso gosto, para embelezar o país, para sublinhara sua poesia (...), para tentar dentro dessa nova actividade, passá-lo a limpo. (...) O Secretariado, sob a nossa direcção, compreendeu sempre a importância do Turismo, (...) fez constante propaganda e apostolado, (...) soube enquadrá-lo, sem exagero nem megalomanias, dentro das preocupações nacionais" (Ferro, I949:10-19).

Enquanto chefe do Secretariado de Propaganda Nacional, António Ferro tinha como missão a fabricação de imagens de um país de convenções estáveis que recusando a contemporaneidade projectava a cultura popular para um passado puro. Para o efeito foi activado um processo de estetização da cultura portuguesa que investiu na idealização do bucolismo, e que via na vida camponesa um espaço de excelência para a transformação de uma Nação pretensamente genuína e pitoresca. Para António Ferro o "pitoresco" era visto como "uma grande atracção, um dos maiores estímulos para viajar, o apelo do desconhecido. Cuidar, pois, cada vez mais, da conservação do grupo regional que seja autêntico" (Ferro, I949: I6). Fundamentado nesta doutrina, proclamou uma estratégia de diferenciação regionalista do produto turístico português e despontou medidas na área da imprensa, com a criação da publicação Panorama - Revista Portuguesa de Arte e Turismo e do património com actividades de conservação/divulgação do património, de classificação de monumentos, de paisagens. Deste conjunto de iniciativas empreendidas pelo Estado Novo, a Exposição do Mundo Português é o momento apoteótico para a (re)produção de um País e que funciona quase como ensaio para o desenvolvimento de um vocabulário turístico. A Exposição apresenta-se como uma "cidade simbólica" como "documento da consciência nacional e da fé com que, no passado glorioso que celebra. A Pátria afirma a certeza inabalável do Futuro!” (Castro, 1940: 49 apud Pires, 2003). Concebida como "cidade da Historia", a exposição de Belém "procura ser o padrão, o documentário, a síntese pela imagem dessa historia (...) não será um museu de coisas mortas, mas um exemplo e uma exaltação das forças permanentes e imortais da nossa raça” (Castro, 1940: 44). O discurso expositivo de forte carácter propagandístico reforça um "Portugal de alegorias e de símbolos" que sugeria uma narração da portugalidade e uma lição para se "saber ser português" (Castro, I940: 2I7 apud Pires, 2003). 
"O espectáculo singular e inolvidável! Pasmava e enternecia reconhecer tantos recursos ignorados; (...) à distância, no tempo, reconhece-se agora, sem grande esforço, que essa parada de valores autênticos representou, além da consoladora revelação (quantos sentiram retemperar-se nela a sua fé nas virtudes nacionais!), um inestimável ensinamento:

- o de que a nossa paisagem doméstica pode ser pitoresca, graciosa, confortável e, até moderna, sem a intervenção de espécimes exóticos” (Panorama I94I, $\mathrm{n}^{\circ}$ I: I5-I6).

Da exposição permaneceu "O Museu da Arte Popular", um pretenso testemunho da portugalidade que recorria a reconstituições dos ofícios rurais para atestar as características "pitorescas" da população lusa. E onde o "povo" representado era o mesmo que era ensinado às crianças nos livros escolares, que vivia no seu "habitat" na "aldeia mais portuguesa de Portugal", que era descrito pelas narrativas turísticas da época e cujo artesanato adornava as hospitaleiras Pousadas Regionais.

As Pousadas de Portugal surgiram para responder à falta de equipamentos de alojamento turístico existentes no país. O Regime propôs um conjunto de Pousadas espalhadas pelo território nacional determinando que "o novo, fosse tanto quanto possível nacional”, e preferencialmente barato, dadas a conjuntura internacional, resultado da i Guerra Mundial. Assim, em vez de promover a construção de hotéis demasiadamente dispendiosos e inoperantes dada a quase inexistente actividade turística da época, estas pousadas responderiam prontamente a uma campanha turística da SPN/sNi. Refere o chefe do S n i que "as nossas Pousadas (...) foram construídas e arranjadas com o intuito principal de servir de modelo a esta nova orientação da indústria hoteleira em Portugal, maquetas animadas, espalhadas pelo pais, onde será fácil colher ensinamentos, aprender e desenvolver certas

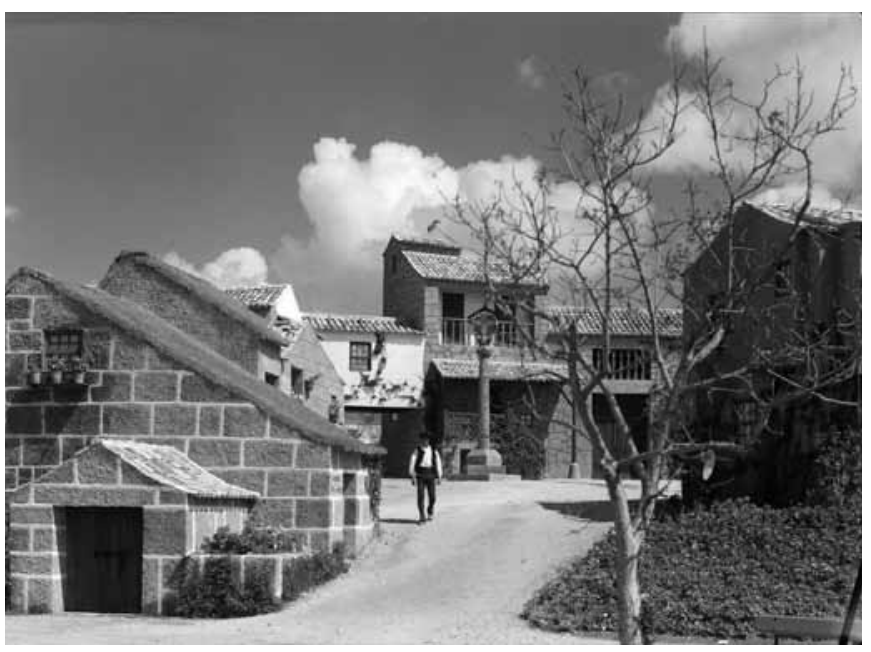
ideias. Procurou-se, portanto, que estes pequenos Hotéis não se parecessem com Hotéis" (Ferro, I949: 68). "Ideias da pequena casa acolhedora, sem

Cena de uma reconstituição viva para o núcleo das Aldeias Portuguesas da Exposição do Mundo Português, Lisboa (1940) carácter de hotel, com móveis diferentes, ambiente diferente, a hospedagem para todos mas que mais parece para cada um" (Ferro, I949: II3). Situadas em meios rurais, estas Pousadas Regionais pretendiam materializar em pleno os princípios da "Casa Portuguesa" de Raul Lino: "O mais forte motivo da campanha para o aportuguesamento da nossa casa, da nossa arquitectura, é um anseio de recuperar a harmonia perdida da paisagem, das cidades de Portugal, o desejo de restabelecer o decoro, pelo menos nas aparências, que deve ter o cenário da nossa vida" (Lino apud Ribeiro, 1994:77).

Esta posição levantou um movimento de resistência da classe de arquitectos da época que para além das questões ideológicas reclamava questões formais de arquitectura que este discurso levantava. Estas questões eram 
especialmente pertinentes quando, num apelo à cristalização de um modelo cultural, o discurso do Estado Novo não garantia diacronicamente, a natural relação entre a produção cultural e a respectiva dimensão construída pelo seu Espaço e Tempo. Ainda mais quando esta "Politica de Espírito" entendia o turista como "um ingénuo aventureiro, um ingénuo descobridor do que já foi feito para ele descobrir" (Ferro, I949:I9) transportando a questão da produção da experiência turística para um domínio altamente paradoxal. Porque de uma forma genérica o Turismo é uma relação empírica que existe numa dimensão do significado cultural e social, e que só se perpétua no contacto facultado pela deslocação física. Nesta base, a partir do momento que as estratégias de promoção turística ameaçam os limites do "autêntico", através de um mecanismo de controlo direccionado para os domínios da produção e da reprodução da experiência turística, na forma como é promovida e acontece e também no conforto, na garantia e na segurança dos turistas, subvertese o princípio da mobilidade. Rossi na obra que marca o fim do postulado modernista, $A$ arquitectura da cidade, levanta precisamente este problema ao afirmar que "um ambiente assim considerado, nada tem a partilhar com a arquitectura da cidade; é concebido como uma cena e enquanto cena, exige ser conservado mesmo nas suas funções; trata-se de um necessário permanecer de funções que apenas pela sua presença salvam a forma e imobilizam a vida e nos estiolam, tal como os falsos locais turísticos de um mundo desaparecido" (Rossi, 2001: 179).

A questão da autenticidade é um tema recorrente tanto na discussão do fenómeno turístico como na disciplina da arquitectura. É um tema profundamente moderno na medida em que "for moderns, reality and authenticity are thought to be elsewhere: in other historical periods and other cultures, in

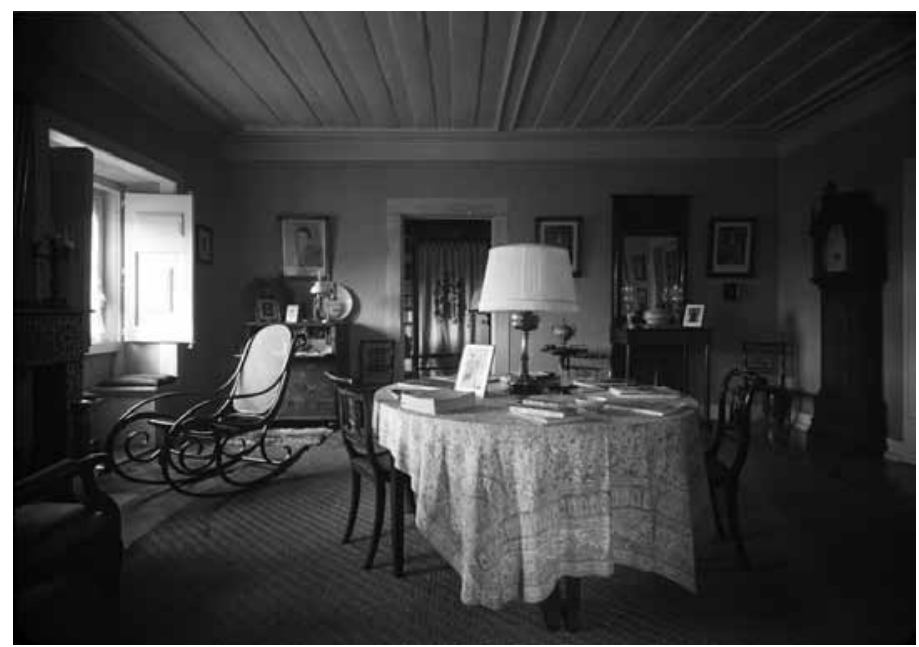

Sala de Estar da Pousada de São Pedro, Castelo de Bode, inaugurada a 1965 
purer, simpler lifestyles" (MacCannel, 1976: 3). Por outras palavras, a rápida e profunda transformação da sociedade, gerou um conflito entre o passado e o presente e futuro. Mas se o Turismo é capaz de gerar este conflito também deverá ser capaz de o resolver podendo até ser visto como potencial mecanismo de reconciliação da sociedade moderna com o passado. Uma espécie de homenagem, em jeito de peregrinação, que atribui uma função aos testemunhos do passado.

Interessa por isso procurar os mecanismos de produção que podem garantir esta continuidade. Henri Lefebvre na obra The Production of Space (Lefebvre, 1974) acrescenta que a produção do espaço se verifica a três níveis: a prática espacial, a representação do espaço e os espaços representativos. $\mathrm{O}$ Turismo existe neste último porque é nesta dimensão que se constroem as fantasias e as narrativas que alimentam a experiencia turística - "space as directly lived through its associated images and symbols, and hence the space of "inhabitants" and "users", but also of some artists and perhaps of those, such as a few writers and philosophers, who describe and aspire to do no more than describe. This is the dominated - and hence passively experience - space whence the imagination seeks to change and appropriate. It overlays physical space, making symbolic use of its objects" (Lefebvre, r991: 39). Por essa razão se quisermos falar da produção da experiência turística é fundamental falar de signo e de onde está este presente na arquitectura.

A arquitectura pode contribuir de duas formas para a experiência turística: a primeira é como da atracção turística no seu sentido material e a segunda tem a ver com o seu contributo para a construção de um sentido de lugar e consequente ambiente. Pegando na definição de atracção turística de Dean MacCannell:

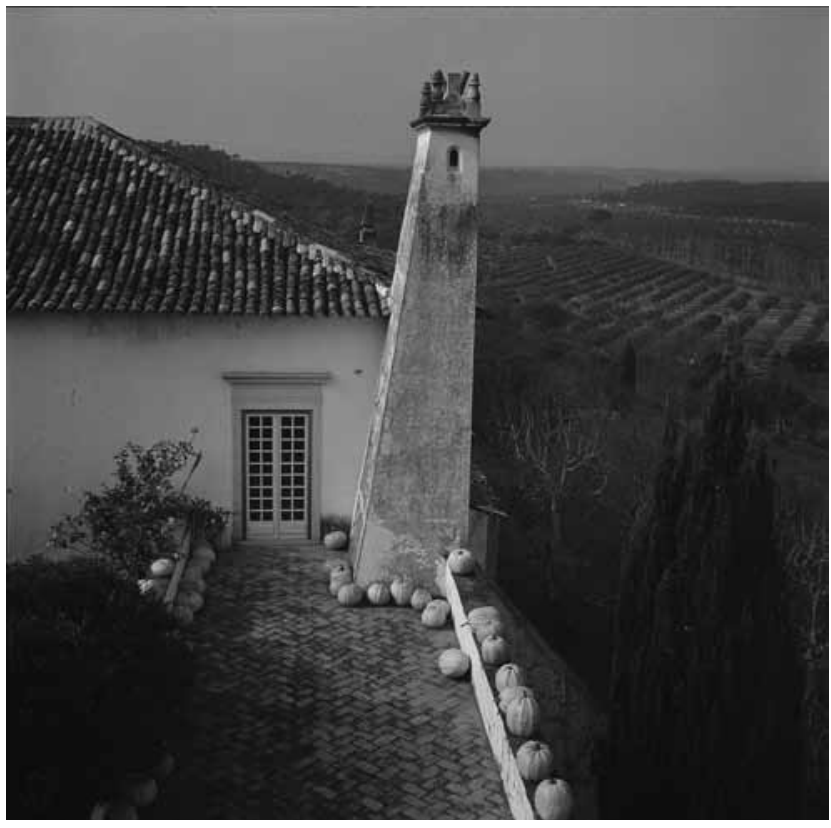

Enquadramento Bucólico da Pousada de São Pedro, Castelo de Bode, inaugurada a 1965 
"an empirical relationship between a tourist, a sight and a marker (a piece of information about a sight)" (MacCannel, I976: 4I) - verifica-se a indispensabilidade do significado e da retórica necessários ao objecto arquitectónico, para ser reconhecido como atracção turística. Porque apesar de um turista poder fazer turismo quando quiser, porque se trata de uma questão de atitude, a arquitectura só faz parte desta dialéctica quando tiver capacidade de retaliar um significado. O signo, como explica Norberg-Schulz é um meio, que permite a comunicação de significado, e que consequentemente faculta uma relação empírica entre o Turista e o objecto arquitectónico. No entanto esse significado tem de ser ímpar, tem de ser capaz de se definir como uma referência vernacular, como é o caso dos monumentos históricos ou até mesmo das cidades. A cidade transforma-se num objecto turístico, quando, e usando as palavras de Norberg-Schulz, "expressa um modo de vida". E para este autor as actividades que participam da cidade estão directamente relacionadas com a ideia de um ambiente - milieu - que a define: "The milieu does not only consist of different meaningful expressions, but of a hierarchy of such. Its single expressions are correlated to particular activities. Often this correlation is a mere matter of habit; we are accustomed to employ certain physical objects on particular occasions" (Norberg-Schulz, I968: 120).

O Turismo deve ser por isso entendido como um fenómeno potencialmente pedagógico a partir do momento que esclarece os diferentes modos de vida. Mais ainda quando o fenómeno do Turismo se generalize, como explica Hans Ibelings no seu ensaio sobre o super-modernismo: "Nowadays, many people in the affluent parts of the world behave like tourists not only when on holiday but also in everyday life. The classic modernist distinction between living, working, recreation and transport has become blurred" (Ibelings, 2002: 147). Ou seja, apesar da experiência turística se caracterizar como uma vivência isolada da "realidade" do lugar, a partir do momento que o fenómeno do Turismo tem influência directa no desenvolvimento desses lugar essas duas dimensões, antes paralelas, passam a inter-relacionar-se. E mais se relacionam quando a mobilidade também se generaliza e quando a sociedade se globaliza. Porque, apesar de no inicio do processo da globalização se anunciar que o mundo se tinha achatado e que "you can now innovate without having to emigrate", a verdade é que à medida que os efeitos da globalização se clarificam, percebe-se que o lugar tem hoje mais importância que nunca. Como explica Richard Florida: "As the most mobile people in human history, we are fortunate to have an incredibly diverse menu of places - in our own countries and around the world - from which to choose. That's important because each of us has different needs and preferences. Luckily, places differ as much as we do" (Florida, 2008: Io).

A atractividade de um lugar é hoje definida pela ambiência e estilo de vida que oferece. De forma a perceber o potencial atractivo da arquitectura, Umberto Eco, no artigo "Function and Sign: the semiotics of architecture" aplica a teoria geral da semiótica ao tema da arquitectura e ao ambiente construído quando esboça uma distinção entre conotativo e denotativo que distingue a função primária da arquitectura das suas funções secundárias. Para 
Eco "the object of use is, in its communicative capacity, the sign vehicle of a precisely and conventionally denoted meaning - its function" (Eco, I997: I82) ou seja, a função primária de um objecto é a sua propria função. Assim sendo além de denotar a sua função, o objecto arquitectónico deve conotar uma determinada ideologia desta mesma função. Desta forma o termo função assume um significado muito mais alargado que se estende a todos os usos dos objectos arquitectónicos, incluindo pois as suas funções comunicativas, simbólicas e sedutoras.

Num outro artigo - "Mass Appeal in Architecure" - Umberto Eco explora mais francamente a capacidade sedutora da arquitectura - "Architectural discourse is phychologically persuasive: with a gentle hand (even if one is not aware of this as a form of manipulation) one is prompted to follow the instructions implicit in the architectural message; functions are not only signified but also promoted and induced, just as certain products and attitudes are promoted through bidden persuasion, sexual associations, etc"(Eco, 1997: 195-196).

O poder persuasivo da arquitectura, como explica Eco, está na sua subtil capacidade condutora. Como construção cultural, a arquitectura funciona como um espelho representativo do lugar, mas o que se sugere agora é que esse espelho funcione nos dois sentidos, que a arquitectura funcione como um elemento condutor para um futuro imaginado. Como já aqui foi explicado, as cidades e as regiões encontram-se hoje num cenário de concorrência directa. O seu desenvolvimento volta-se por isso para estratégias de projecção e só através da clarificação da sua identidade é que uma cidade se consegue posicionar. O Guggenheim de Bilbao é um exemplo paradigmático desta instrumentalização da arquitectura através do seu potencial mass appeal.É um exemplo perfeito de como a arquitectura ultrapassa a sua função primária - a de museu - e catalisa, através de uma arquitectura conotativa, a própria ideia da cidade onde se insere. Assume-se como mote para a mudança, sugerindo e direccionando o caminho a percorrer.

Mas este museu é também um exemplo carismático para entender os perigos desta estratégia. Para Sicco van Gelder, consultor de uma empresa de Place Branding, o caso do Gugenheim de Bilbao gera o que chama, neste universo de marketing o "efeito usurpador", "something like the Guggenheim should be a benefit brand, should be a component of a whole brand of a place and should bring something exclusive to that brand which the brand it self it doesn't have (...). But the problem is that the moment that component brand becomes more important than the place it self it actually, it sucks every brand equity out." Sicco van Gelder considera que podem existir dois cenários possíveis na participação do arquitecto no processo, ou o "valor" da marca é introduzido num projecto de arquitectura pelo seu enunciado, ou seja, como problemática de um projecto que vai ser desenvolvido; ou um determinado arquitecto é escolhido pelo que representa publicamente e pelo que já deu mostras de conseguir fazer, e aqui entra normalmente o chamado star system da arquitectura. O problema é que esta última corre o risco de produzir o efeito contrário na produção de identidade urbana, criando aquele que é o chamado 
efeito de "homogeneidade diferenciada". Como expõe Naomi Klein, em "No Logo": "The terrible irony of these surrogates, of course, is how destructive they are providing to be the real thing: to actual own centers, (...) to the non-Disney version of public spaces, to art as opposed to synergized cultural products and to a free and messy expression of ideas" (Klein, 2002: 152).

Também para a dupla de arquitectos Diller e Scofidio, a aposta dos agentes turísticos em proporcionar uma sensação de familiaridade através do reconhecimento, numa analogia às lógica de franchising, subverte o princípio da mobilidade, no momento que quebra a relação circular que o turismo deve completar com o domínio doméstico: "Being sick of home may lead to travel which may, in turn, lead to homesickness, wich will surely lead back home. This circular structure is the basis of travel. Tourism interrupts this circuit by eliminating the menaceof the unfamiliar: that which produces homesickness" (Diller et Scofidio, I994: 4I).

O Turismo é um dos fenómenos que exibe maior potencial da cultura contemporânea. Assenta num conjunto de práticas sociais e criativas mas distingue-se como actividade económica, pela sua capacidade de gerar riqueza através da comercialização da experiência e do seu carácter mobilizador de deslocação do cliente ao produto, que é um lugar. A matéria-prima explorada no turismo é, portanto, o próprio espaço. As especificidades dos lugares, reflexos da sua identidade e riquezas naturais ou culturais, são determinantes do seu potencial turístico. E é neste domínio que a produção turística verdadeiramente se potencia, enquanto mecanismo benéfico para o desenvolvimento e estruturação espacial de um território. Não se pode por isso continuar a encarar este fenómeno como uma simples fonte de rendimento que manobra na lógica do artifício para acompanhar as tendências. O lugar, mesmo enquanto produto, é sempre caracterizado por uma grande complexidade inerente que o Turismo estende para além das suas características próprias, acrescentando um novo nível de auto consciência que gera novos níveis de complexidade e que constituem matéria para uma contínua e sustentável construção dos lugares. 
Referências bibliográficas

Diller + Scofidio (1994), Back to the front: Tourisms of War. New York: Princeton Architectural Press.

Eco, Umberto (1986), Travels in Hyper- Reality. London: Picador.

Eco, Umberto (1997), Function and Sign: The Semiotics of Architecture em Rethinking Architecture (Neil Leach). London: Routledge .

Ferro, António (1949), Artes decorativas: palestra de 1940, e discurso da Exposição de Artes Decorativas em1949. Lisboa: Edição s N I.

Florida, Richard (2008), Who's Your City? New York: Basic Books.

Harries, Karsten (1998), The Ethical Function of Architecture. Cambridge: M I T Press.

Ibelings, Hans (2002) Supermodernism

Architecture in the Age of Globalization. Rotterdam: Nai Publishers.

Klein, Naomi (2002), No Logo. New York: Picador.

一

Klingmann, Anna (2007), Brandscapes. Architecture in Experience Economy. Cambridge: м I т Press.

Le Corbusier (2000), Urbanismo. São Paulo: Martins Fontes.
Lefebvre, Henri (1991), The Production of Space. Oxford: Basil Blackwell Publishing.

MacCannel, Dean 1976 The Tourist: A New Theory of the Leisure Class. New York: Schocken Books.

-

Norberg-Schulz, Christian (1968), Intentions in Architecture. Cambridge: мi т Press.

Pires, Ema Cláudia (2003), O Baile do Turismo: Turismo e Propaganda no Estado Novo. Lisboa: Caleidoscópio.

-

Portas, Nuno (2008), Arquitectura para Hoje 1964 seguido de Evolução da Arquitectura Moderna Portuguesa 1973. Lisboa: Livros Horizonte.

-

Ribeiro, Irene (1994), Raul Lino: Pensador Nacionalista da Arquitectura. Porto: Faup Publicações.

Rossi, Aldo (2001), A Arquitectura da Cidade. Lisboa: Edições Cosmo.

-

Santos, José Manuel Figueiredo (2001),

Transformação Contemporânea da Experiência

Turística. Dissertação de Doutoramento em Sociologia da Cultura, Faculdade de Ciências Sociais e Humanas, Universidade Nova de Lisboa.

Sobral, José Manuel (1999), “Da casa à nação: passado, memória, identidade", Etnográfica, 3 (1): 71-86.

Urry, John (1990), The Tourist Gaze. London: Sage.

\section{Créditos das imagens}

Fotografia Turística do Guggenheim, Bilbao. Imagem de Pedro Augusto de Azambuja Varela

Cena de uma reconstituição viva dos ofícios rurais para o núcleo das Aldeias Portuguesas da Exposição do Mundo Português, Lisboa (1940). Colecção Estúdio Mário Novais, Fundação Gulbenkian

Cena de uma reconstituição viva para o núcleo das Aldeias Portuguesas da Exposição do Mundo Português, Lisboa (1940). Colecção Estúdio Mário Novais, Fundação Gulbenkian

Sala de Estar da Pousada de São Pedro, Castelo de Bode, inaugurada a 1965.Colecção Estúdio Mário Novais, Fundação Gulbenkian

Enquadramento Bucólico da Pousada de São Pedro, Castelo de Bode, inaugurada a 1965. Colecção Estúdio Mário Novais, Fundação Gulbenkian 